\title{
Echinococcus vogeli
}

National Cancer Institute

\section{Source}

National Cancer Institute. Echinococcus vogeli. NCI Thesaurus. Code C122291.

A species of cyclophyllid tapeworms in the family Taeniidae. Common in the neotropics,

E. vogeli has a lifecycle that involves the paca as the intermediate host and the bush dog as the definitive host. This species causes polycystic echinococcosis in humans. 